\title{
EL ESPEJO COMO METÁFORA DE LA ALTERIDAD Y DE LA INTERSUBJETIVIDAD EN LA OBRA DE CARMEN MARTÍN GAITE
}

\author{
THE MIRROR AS A METAPHOR OF ALTERITY AND INTERSUBJECTIVITY \\ IN CARMEN MARTÍN GAITE'S WRITING
}

\author{
RUBEN VENZON \\ Universidad de Valladolid \\ ruben.venzon@gmail.com
}

\begin{abstract}
RESUMEN: El motivo del espejo aparece con mucha frecuencia a lo largo de la obra, tanto narrativa como ensayística, de Carmen Martín Gaite, donde adquiere relevantes implicaciones metafóricas y simbólicas. Con el objetivo de entender el alcance de este leitmotiv, en el presente artículo se analiza, primero, a partir de la teoría psicoanalítica de Lacan sobre el "estadio del espejo", cómo la autora retrata la problemática relación del individuo con su propia imagen especular para demostrar la insuficiencia de la subjetividad en sentido cartesiano. Posteriormente, mediante la referencia a las reflexiones de la escritora sobre la búsqueda del interlocutor y la comunicación interpersonal, se estudia, acudiendo al concepto lacaniano de "Gran Otro", el proceso de metaforización del espejo y su significación como símbolo del semejante. De este modo se explica, por último, la importancia que la autora le otorga al papel de la alteridad y de la intersubjetividad en el desarrollo identitario del individuo así como en la realización personal del mismo.
\end{abstract}

Palabras Clave: Carmen Martín Gaite; espejo; alteridad; intersubjetividad; identidad

ABSTRACT: The mirror motive can be found frequently in Carmen Martín Gaite's writing, both in her fiction as well as in her essays, and contains relevant metaphoric and symbolic implications. In order to understand its importance as leitmotif, this article firstly analyzes, based on Lacan's psychoanalytic "mirror stage" theory, how the author portrays the problematic relationship between the individual and its own specular image to prove the insufficiency of subjectivity in the Cartesian sense. Subsequently, by means of writer's reflections about both the search for the interlocutor and the interpersonal communication, the process of 
the metaphorization of the mirror and its significance will be studied emanating from the Lacanian "Big Other" concept. The fact that the mirror eventually symbolizes the other renders it possible to, lastly, explain the relevance Carmen Martín Gaite accords to the role of alterity and intersubjectivity in the self-development as well as in the personal realization of the subject.

KeYWORDS: Carmen Martín Gaite; Mirror; Alterity; Intersubjectivity; Identity

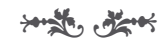

Mas busca en tu espejo al otro, al otro que va contigo.

A. Machado, Nuevas canciones

\section{Carmen Martín Gaite y los espejos}

Desde tiempos inmemoriales, el espejo ejerce una gran fascinación sobre el ser humano: sus resonancias mágicas siguen vigentes aún hoy día en el imaginario colectivo y sus misterios parecen inagotables. De ello queda constancia no solo en la mitología y el folklore, sino también en la filosofía, el arte y la literatura de todas las épocas, que le otorgan rasgos ambivalentes e incluso contradictorios, además de valores metafóricos relevantes. Símbolo para algunos de una sabiduría que da acceso al conocimiento del individuo y del mundo, representa para otros una peligrosa trampa de engaño y seducción. El espejo se configura a la vez como el lugar donde pueden hallarse la verdad y la mentira, pues en su interior se confunden la ilusión de la realidad y la percepción de lo irreal, poniendo a prueba los límites de la razón.

Dentro de la variopinta geografía de los objetos que califican la obra de Carmen Martín Gaite, el espejo ocupa sin duda un lugar privilegiado. Así lo atestiguan sus frecuentes apariciones tanto en la narrativa como en algunos ensayos de la autora, su gran versatilidad y las implicaciones simbólicas que va adquiriendo con el paso del tiempo. Este elemento ha de considerarse, pues, como un auténtico leitmotiv a lo largo de la trayectoria literaria de la escritora, quien introduce en sus narraciones numerosas variantes del mismo, ajustándolas a distintas y renovadas funciones. Dependiendo de la ambientación y las circunstancias, los espejos que presenta pueden ser de cuerpo entero, de pared, lunas de armario, espejitos portátiles, espejos retrovisores o incluso simples superficies lúcidas. Dicha variedad no es nada casual, ya que le permite a la autora focalizar la atención sobre aspectos diferentes a partir de un punto de vista inédito. ${ }^{1}$

\footnotetext{
${ }^{1}$ La importancia de algunos espejos es sugerida a veces por la minucia con que la autora los describe. Recuérdese, en Nubosidad variable, el inquietante espejo del piso de la Calle de la Amargura, que debido a su macabra ornamentación inquieta a Mariana (Martín Gaite 2012c: 93). No me-
} 
En un primer momento, el uso del espejo responde a una necesidad de tipo más bien formal, aunque en dicha modalidad ya aparece una conexión directa con la interioridad del observador. De este modo, se va introduciendo la dimensión psicológica de quien mira y, en particular, el tema de la problemática relación del individuo con su propia imagen especular debido al descubrimiento de la alteridad inherente a todo ser humano. De hecho, los personajes de Carmen Martín Gaite suelen recurrir al espejo para apuntalar una identidad vacilante o amenazada, pero el reflejo que este les devuelve no se corresponde con sus expectativas, provocando en ellos decepción y desasosiego. Tal actitud puede explicarse a partir de la teoría de Lacan sobre el stade du miroir -o "estadio del espejo"-, para subrayar cómo la escritora capta el funcionamiento de determinadas fantasmáticas de identificación y dominio relacionadas con la identidad, registrando sus nefastas consecuencias a nivel emotivo.

Dadas estas premisas, se observa posteriormente cómo la autora empieza a desarrollar el poderoso simbolismo del espejo, empleándolo en su vertiente metafórica. En efecto, una vez asumida la insuficiencia de la subjetividad en sentido cartesiano gracias a la constatación de la multiplicidad y la fragmentación del sujeto, Carmen Martín Gaite reclama -tanto en los ensayos como en la narrativa- la búsqueda del interlocutor y la práctica de la interlocución como únicas vías para la realización del individuo. Es así como el espejo se convierte, a partir de una experiencia física de tipo visual -esto es, el acto de verse reflejado-, en metáfora del otro, del semejante. Haciendo nuevamente referencia a la teoría psicoanalítica, este fenómeno se concibe como paso del registro de lo Imaginario a la dimensión de lo Simbólico, lugar del Gran Otro lacaniano y de la Palabra, para remarcar el rol determinante y estructural de la intersubjetividad en la formación identitaria del sujeto.

\section{EL REFLEJO Y LA MIRADA}

La naturaleza del espejo se manifiesta en su capacidad reflectante, que constituye indudablemente su rasgo definitorio principal. Para ser más exactos con respecto a su función se puede definir como "prótesis", es decir, un "aparato que extiend[e] el radio de acción de un órgano" (Eco 1988: 18). En este sentido, el ojo humano se beneficia de su mediación para ver cosas que el campo visual no puede abarcar por razones anatómicas obvias, como lo que está a sus espaldas, lateralmente o asimismo proporcionarle otra perspectiva diferente de la frontal. Gracias a tales ventajas, este elemento se ha usado a menudo en literatura como medio descriptivo que le aporta al texto cierto perspectivismo, ampliando sus posibilidades ilustrativas al retratar indirectamente la apariencia de personas, lugares o situaciones. Carmen Martín Gaite también acude a este recurso mimético, especialmente a la hora de introducir a personajes y ambientes de forma neutral para transmitir su aspecto más que su índole (Pérez 1995: 50; De

nos sugestivo resulta el espejo del comedor de la casa de Leonardo en La Reina de las Nieves, cuyo decorado llama la atención del protagonista invitándole a la reflexión (Martín Gaite 2011a: 138). 
Bleeker 2006; Mora 2013: 39). Al respecto, una aplicación bastante frecuente es revelar lo que está detrás de uno, cuando, por ejemplo, la escena se desarrolla en un coche, como resulta evidente en este breve pasaje de Entre visillos (1958) en el que se da cuenta de la actitud de un taxista hacia una de sus pasajeras: "Enrique de vez en cuando levantaba los ojos y se sonreía un poco en el espejito mirando a Candela que venía en el silletín" (Martín Gaite 1983: 182). La misma dinámica se aprecia si el personaje se encuentra en una peluquería o delante de un tocador, según puede observarse en una anotación del protagonista de La Reina de las Nieves (1994) donde se refiere a sí mismo sentando en el sillón de un barbero: "en el espejo de enfrente se reflejaban un rostro enjabonado y una mirada cómplice" (Martín Gaite 2011a: 244). En estos escenarios recurrentes, ${ }^{2}$ el espejo le ofrece una vía de escape visual a quien por obligación tiene que mirar hacia delante, dándole acceso parcial a lo invisible.

Por otra parte, la mayor aportación de este instrumento consiste en descubrirle al hombre su propia imagen -de otro modo inaccesible- posibilitando la visión integral de lo que no se puede captar o, a lo sumo, solo parcialmente: el conjunto del cuerpo humano y, sobre todo, el rostro. Esta otra aplicación, también descriptiva, no está exenta de implicaciones a nivel personal, puesto que permite apreciar las especificidades de cada uno y asumirlas. Los ejemplos de este fenómeno también abundan en la narrativa de la autora y comparten el hecho de que los personajes se ven por sí mismos desde fuera, pudiendo constatar autónomamente su apariencia física y emitir un juicio. ${ }^{3}$ El caso de la protagonista del relato "Tarde de tedio" (1970) ilustra con claridad el fenómeno: "A esta luz cruda se revelan netamente los cuarenta años de la mujer, que, despeinada y en combinación ante el espejo se pasa ahora los dedos con desaliento por otra importante zona de su cuerpo donde el tiempo ha hecho estragos: la cabeza" (Martín Gaite 1986: 153). De esta manera, la autora introduce la mirada humana y la visión del contexto como partes integrantes de la narración, poniendo de relieve la importancia de la imagen visual en su universo literario. Con todo, esta función descriptiva del espejo se queda en un plano que podría calificarse de "superficial", es decir, que no va más allá de lo visible, porque el objetivo de momento- es proporcionar unas instantáneas que esbocen algunos rasgos significativos y no ahondar en cuestiones psicológicas íntimas. Al considerar tan

\footnotetext{
2 Situaciones muy parecidas se desarrollan en "Tarde de tedio", donde la complicidad entre la clienta y la peluquera se manifiesta a través de un intercambio de miradas en el espejo (Martín Gaite 1986: 155); en "El pastel del diablo", cuando la expresión atónita de Sorpresa queda reflejada en el espejo de un tocador en el que se está mirando un misterioso hombre, el cual, sin embargo, no repara en ella (Martín Gaite 2009b: 142); en Caperucita en Manhattan, mientras Sara Allen se dirige a casa de la abuela en la limusina de Edgar Woolf y el chófer la observa por el espejo retrovisor (Martín Gaite 2012b: 186).

${ }^{3}$ Además del fragmento citado a continuación, existen otros ejemplos de este fenómeno: en Nubosidad variable, Sofía se encuentra con Guillermo en Londres y, en el hostal donde se alojan, la mujer consigue espiarse a sí misma en un armario de luna (Martín Gaite 2012c: 179 y 364); en Irse de casa, Amparo Miranda llega a un hotel tras un largo viaje y nota en el espejo del hall los efectos del cansancio en su cara (Martín Gaite 2012d: 39); en Los parentescos, Baltasar se observa en el espejo del pasillo acompañado por Loreto, valorando la actitud íntima que tiene con la chica (Martín Gaite 2001: 244).
} 
solo evidencias, todavía no se pone en tela de juicio la imagen especular ni se aprecian en los personajes reacciones que delaten una implicación profunda o una participación emotiva destacable.

Sin embargo, la interacción de los personajes de Carmen Martín Gaite con los espejos nunca resulta del todo aproblemática y siempre remite a su dimensión interior, ya que, "la mirada al espejo determina que se tenga una imagen [...] muy diferente de la que se percibe a través de la mirada directa" (Martinell Gifre 1996: 122). De ahí que a menudo el reflejo resulte distorsionado y provoque estupor o hasta miedo. Efectivamente, dentro del espejo -lugar del doble por antonomasia-, parecen mezclarse "realidad y alucinación, [porque] los mundos ordenados con estos instrumentos de precisión revelan una reversibilidad de las cosas: la certeza de lo aparente, la incertidumbre de lo existente" (Baltrusaitis 1988: 282). Aun así, desde el punto de vista fenomenológico, cabe aclarar que dicha anomalía no depende del espejo per se, pues este "no traduce", sino que "registra lo que incide en él tal como en él incide" y, sobre todo, "no interpreta los objetos" (Eco 1988: 18). Partiendo de esta premisa fundamental, puede inferirse que es el observador quien, al proyectar en él sus latencias, modifica inconscientemente la calidad y la naturaleza de la imagen. Por lo tanto, a pesar de la garantía de exactitud que por definición ofrece, el reflejo nunca está libre de connotaciones personales, porque el ojo humano interpreta lo visible a partir de emociones y estados de ánimo que alteran su recepción (Gambazzi 1999: 1-7). De tal manera que el espejo "no refleja, pues, únicamente unos rasgos físicos, sino una actitud interior" (Melchior Bonnet 1996: 125); por eso, su contenido parece anómalo, ilógico o incluso espantoso de acuerdo con la condición mental de quien mira en él.

En los textos de la escritora, este aspecto se aprecia sobre todo cuando el espejo sirve para la descripción indirecta de determinados lugares, donde la percepción emotiva del personaje -es decir, el valor interpretativo de la miradainfluye en la apariencia objetiva del espacio y contribuye a su modificación. Al no dar cuenta fidedigna de la realidad, el reflejo registra las sensaciones que el individuo proyecta sobre ella y el entorno, añadiéndole un toque de subjetivismo a veces muy marcado que, normalmente, tiende a lo irreal y lo onírico. Piénsese, a modo de ejemplo, en la percepción de Pedro, protagonista de "La mujer de cera" (1954), al observar su cuarto a través del espejo:

Solamente los ojos me atrevía a volverlos al más pequeño rumor, fijándolos en la luna del armario, donde se reflejaba neblinosamente la pared del otro lado con el rectángulo de la puerta, y así esperaba, con la cabeza tensa y el corazón parado, la más impresionante aparición. [...] Reflejada en la luna del armario, gris, acuosa, soñolienta, fui reconociendo la habitación. (Martín Gaite 1986: 183)

Aquí, la adjetivación empleada en la descripción de la habitación designa más la condición física y moral del hombre -perturbado por los efectos del alcohol y el miedo- que el aspecto real del lugar donde se encuentra. 
De modo que, una vez constatada la imposibilidad de ver el mundo tal y como es, debe reconocerse que el espejo devuelve una visión parcial que siempre remite a una interpretación subjetiva. Así pues, este instrumento empieza a abandonar la función mimética anteriormente descrita para dejar paso a un planteamiento del asunto mucho más complejo: ahora en su interior puede verse cómo aflora y se traslada el inconsciente de los personajes. ${ }^{4}$ Por otra parte, el fenómeno no ha de sorprender, ya que, a pesar de su supuesta precisión óptica, no existe espejo sin la mirada del espectador, la cual nunca está exenta de condicionamientos y nunca deja de plasmar lo que abarca.

\section{DEL DESCONOCIMIENTO A LA IDENTIFICACIÓN}

El espejo nunca alberga la cosa en sí misma -por naturaleza inaprensible-, sino una representación de lo real alterada por la interioridad del individuo, y se transforma en un soporte que revela los recovecos del alma humana. Por lo tanto, la función principal que desempeña en la obra de Carmen Martín Gaite resulta estar mucho más relacionada con la cuestión identitaria que con la mímesis. Los personajes creados por la autora están empeñados en la dificultosa tarea de reconstruirse a sí mismos y, para ello, ante un impasse vital, acuden al espejo en busca de un asidero. No obstante, este nunca proporciona una solución definitiva a la crisis del individuo, sino que, muy al contrario, suele provocar un cuestionamiento aún mayor de la identidad. En efecto, las imágenes que devuelve, al resultar irreconocibles o extrañas, plantean un inesperado desconocimiento $y$, pese a la ciega fe en un sujeto monolítico de raigambre cartesiana, destacan la alteridad que estructuralmente concierne al ser humano.

Desde el punto de vista extraliterario, es tan solo con la llegada del psicoanálisis cuando se consigue arrojar luz sobre la problemática relación del hombre con su reflejo: la corriente psicoanalítica aclara por primera vez el papel determinante del espejo en la formación y en la articulación del sujeto ya desde muy temprana edad (Freud 1981b; Lacan 2008). Más concretamente, la mayor aportación al respecto se debe a Jaques Lacan, quien, en un ensayo de 1963 titulado El estadio del espejo como formador de la función del yo, teoriza el stade du miroir -o "estadio del espejo"-. En esta etapa fundacional, el niño es todavía incapaz de coordinar sus movimientos corporales y se percibe de manera fragmentaria, pero puede reconocerse visualmente en el espejo como unidad. Tal reconocimiento provoca en él una reacción jubilosa, ya que la imagen especular,

\footnotetext{
${ }^{4}$ La relación entre el espejo y la percepción irreal del entorno se explicita también en los siguientes pasajes narrativos: en Entre visillos, durante el velatorio de don Rafael Domínguez, Pablo Klein, claramente alterado por la presencia de Elvira, se ve envuelto en una atmósfera borrosa, donde el espejo de un aparador reafirma su confusión (Martín Gaite 1983: 59); en "Las ataduras", Benjamín, insomne debido a la preocupación por su hija, al incorporarse en la cama, ve la habitación distorsionada en el espejo (Martín Gaite 1986: 90); en Nubosidad variable, Sofía rememora el velatorio de la madre, acordándose de cómo antaño lo había observado todo a través del espejo de un gran armario y de cómo el reflejo deformado del cuarto la había acabado distrayendo del duelo (Martín Gaite 2012c: 363). En cuanto a la dimensión onírica, recuérdese sobre todo la escena de "El balneario" en la que Matilde, tras despertar de una angustiosa pesadilla, se dirige al espejo y experimenta una especie de prolongación de su sueño (Martín Gaite 1988: 57).
} 
al proporcionarle una visión unitaria de sí mismo, compensa la falta de control motor y recompone virtualmente un cuerpo que siente fragmentado -el corps morcelé-, anticipando sobre él un dominio ilusorio aún por alcanzar:

... el "estadio del espejo" es un drama cuyo empuje interno se precipita de la insuficiencia a la anticipación; y que para el sujeto, presa de la ilusión de la identificación espacial, maquina las fantasías que se suceden desde una imagen fragmentada del cuerpo hasta una forma que llamaremos ortopédica de su totalidad -y hasta la armadura por fin asumida de una identidad alienante, que va a marcar con su estructura rígida todo su desarrollo mental. (Lacan 2008: 102-103)

Sin embargo, esta primera identificación "imaginaria" -es decir, relativa a la imagen visual-resulta profundamente alienante: el niño se reconoce en una imagen que no se adhiere a su ser, sino que está proyectada hacia fuera sobre una superficie ajena y, por lo tanto, es "otra" (Recalcati 2016: 21). Así, ya desde el primer momento, la identidad pasa inevitablemente por la alteridad, de tal manera que el carácter del sujeto se basa en una alienación intrínseca. Esta configura el "yoideal", una armadura ficticia de la personalidad que influye sobre el posterior desarrollo del individuo: se trata de lo que Lacan denomina moi frente al sujeto del inconsciente entendido como sujeto del deseo, el je (Recalcati 2016: 5).

La dinámica del stade du miroir encuentra sorprendentes correspondencias en algunos pasajes narrativos de la autora, donde esta consigue plasmar muchos elementos clave a la hora de adentrarse en los mecanismos de la formación identitaria. Carmen Martín Gaite hace hincapié sobre todo en la otredad que entraña el reconocimiento en la imagen especular, con la cual los personajes no consiguen identificarse sino después de experimentar un súbito desconocimiento y cierta perplejidad ante una figura que parece no pertenecerles. Asimismo, destaca la reacción que deriva de la posterior identificación y las fantasías de dominio que se gestan en la mente de los protagonistas a partir de entonces. El ejemplo más paradigmático al respecto se encuentra en "El balneario" (1955), donde la protagonista Matilde, tras despertar bruscamente de una angustiosa pesadilla, se dirige hacia el espejo de su habitación:

La señorita Matilde se levanta y se va al espejo, atraída por una fuerza misteriosa e irresistible. La mujer de dentro de la luna se levanta también y avanza hacia ella, lenta, solemne, fantasmal. Se quedan paradas una frente a otra y se miran absortas, como haciendo memoria, como si no pudieran conocerse. Fijándose bien, la señorita Matilde advierte, de pronto, que la de dentro tiene en los ojos un poco de burla, como si hubiera adivinado todas las fantasías que ella está urdiendo con tanta seriedad y le siguiera la corriente por obligación. La mujer del espejo se pasa horas y horas agazapada en lo oscuro y, cuando se asoma, viene pensando en viajes que ha hecho desde su rincón. A la señorita Matilde le da envidia, porque le parece que sabe más cosas que ella; pero luego reflexiona y se siente orgullosa de envidiarla, porque, al fin y al cabo, es como estarse envidiando a sí misma. Y entonces se ríe, complacida, y señala a la imagen con el dedo índice: "Yo soy esa, yo soy esa. Yo soy tú". Y le gusta ver que la de dentro se ríe y hace los mismos gestos, como una esclava. (Martín Gaite 1988: 58) 
En el fragmento se plantea un desdoblamiento que enfrenta a la "mujer de dentro de la luna" con la de fuera (Paoli 1998). Las dos se miran, pero no llegan a reconocerse. El espejo se convierte en el lugar del desconocimiento, ya que no hay identificación por parte de la protagonista con su imagen reflejada. En todo esto, la "mujer del espejo" parece mofarse de las fantasías amorosas de Matilde, debido a una especie de conciencia superior que le otorga su posición privilegiada. Al sentir envidia por los supuestos conocimientos de la otra, Matilde se da cuenta de que es ella misma y así lo declara. Por lo tanto, finalmente, sí hay reconocimiento, pero la identificación no puede prescindir de la experiencia de la alteridad, que aquí se admite y acepta. Es fácil reconocer en estas líneas una reproducción de las fases del stade du miroir. ${ }^{5}$ En particular, el pasaje evidencia cómo el reflejo de uno mismo siempre es "otro" y lo destaca lingüísticamente mediante el empleo del pronombre "esa". Además, la asunción de la imagen especular como propia origina en la protagonista cierta alegría y una sensación de poder que se manifiestan a través de una especie de juego mimético -muy relacionado también con el Fort/Da (Freud 1981b: 2512)-, cuyo placer deriva de la identificación imaginaria y se explica a partir de una presunción de poder frente a la impotencia del corps morcelé.

\section{LA FASCINACIÓN DE LO ESPECULAR}

La falsa creencia de que el espejo refleja las cosas tal y como son le brinda al individuo la engañosa seguridad de conocerse a sí mismo y de corresponderse con las aspiraciones fantasmáticas del "yo-ideal", elemento que, en cambio, "sitúa la instancia del 'yo', aun antes de su determinación social, en una línea de ficción, irreductible para siempre por el individuo solo; o más bien, que solo asintóticamente tocará el devenir del sujeto" (Lacan 2008: 100). Se trata, pues, de una proyección idealizada por definición inalcanzable, puesto que procede desde fuera y se gesta a partir de la ruptura insanable que separa al sujeto de su reflejo (Recalcati 2016: 24). Entonces, el peligro reside en que la imagen especular, al proporcionar una ilusión de unidad que compensa momentáneamente el carácter fragmentario del sujeto, ejerce sobre el mismo una fascinación narcisista que le induce a confiar en la autonomía de la subjetividad.

Por su parte, Carmen Martín Gaite ilustra de forma magistral cómo el ser humano tiende a caer en las trampas de lo especular y cómo, al constatar su falacia, sufre inevitables consecuencias. No son infrecuentes los ejemplos de personajes que, estancados en una crisis vital o presas de alguna dificultad que les hace dudar de sí mismos, acuden al espejo como si este pudiera ofrecerles ayuda. Tal actitud se basa en la convicción de que la imagen especular proporciona

\footnotetext{
${ }^{5}$ La misma dinámica especular puede apreciarse en el relato "La oficina", donde la protagonista Mercedes se encierra a diario en el cuarto de baño y empieza a contemplar su propio rostro. En un primer momento tiene dificultades para reconocerse, pero al final se lleva a cabo la identificación, la cual, sin embargo, resulta dolorosa, porque pasa por la experiencia del desconocimiento, de la alteridad (Martín Gaite 1986: 25). Resulta interesante, en este caso, notar que el proceso de construcción de la identidad sea reiterativo y se lleve a cabo día tras día.
} 
una especie de garantía identitaria. No obstante, debido al carácter fantasmático de semejante pensamiento, quienes buscan amparo en el espejo no suelen encontrar ningún tipo de sustento, sino tan solo la desagradable confirmación de su propia alienación. Este comportamiento está reproducido muy claramente en La Reina de las Nieves, cuando Leonardo Villalba decide llamar por teléfono a Casilda Iriarte con el pretexto de recuperar la antigua mansión de su abuela. Antes, el protagonista siente la necesidad de escoger un escenario adecuado y se dirige al cuarto de la recién difunta madre, donde hay un espejo de cuerpo entero que le permite "supervisar actitudes y gestos desmandados". Allí, el joven realiza una especie de ritual previo:

Completo la transgresión encendiendo una vela en la palmatoria de plata y colocándola junto a la foto de los acantilados. Apago el resto de las luces, menos la de una lámpara baja, y busco en la radio música clásica. Mozart. Está bien. Bajo el volumen y me acerco al espejo, donde mi figura se difumina. Me favorece el color avellana, con las puntas de la camisa blanca asomando. Me acaricio el pelo, muy suave al tacto. Procuraré que tampoco resulte áspero el tono de mi voz. (Martín Gaite 2011a: 246)

Con cierto aire narcisista, Leonardo siente la necesidad de arreglarse para coger confianza en sí mismo ante una situación que le desestabiliza. El supuesto control que cree ejercer sobre el entorno y sobre la imagen especular -la cual, no obstante, se acaba difuminando debido a su vacilación e inestabilidad-constituye para él un elemento de seguridad. Sin embargo, se trata de un dominio ilusorio que se desmorona en cuanto empieza a conversar con Casilda, interlocutora imprevisible y enigmática. Es entonces cuando Leonardo vuelve a acudir al espejo:

Me ladeo hacia el espejo en busca de alianza y me encuentro con una figura atenuada e indolente, a punto de disiparse. No me puedo dejar anular de esta manera. Porque ella no me haya visto nunca no voy a claudicar de mi identidad. (Martín Gaite 2011a: 252)

La aparente seguridad del joven se desintegra nada más empezar la conversación, que comienza de forma abrupta estallándose contra la calma de la mujer ante su desasosiego. De nada le vale haber ensayado palabras y ademanes. El espejo se convierte, entonces, en un aliado donde el protagonista pretende encontrar apoyo, pero se revela un amigo falaz. La imagen que le devuelve borra de un plumazo todas sus certezas. De este modo, la insuficiencia del reflejo como medio de sustento identitario resulta aquí evidente: Leonardo llega a dudar de sí mismo cuando Casilda afirma no haberle visto nunca, introduciendo así la cuestión fundamental del deseo, que consiste en la necesidad de reconocimiento por parte del otro. A pesar de la desazón, el protagonista reacciona y retoma las riendas del diálogo. Con todo, la mujer le sigue resultando bastante hermética y a cada frase consigue perturbarle. Por esta razón, aunque hacía poco le defraudara, decide recurrir una vez más al espejo: 
Al otro lado del hilo la mujer se ríe bajito. ¿Se ríe realmente? ¿Por qué? ¿Qué está pasando? Y lo que sea, ¿pasa de verdad? Necesito hacerme con el sueño, dirigirlo. Me miro otra vez al espejo, como si quisiera apuntalar una identidad que vuelve a desmoronarse. (Martín Gaite 2011a: 258)

La imposibilidad de penetrar en los pensamientos de Casilda y la pretensión de domar lo indomable -el sueño- atormentan al joven. Una vez más, el recurso al espejo responde a la necesidad de compensar alguna carencia identitaria: el protagonista procura remediar el drama de la fragmentariedad sin tener en cuenta la naturaleza escindida del sujeto. El fracaso es inevitable, puesto que, desde el punto de vista psicoanalítico, la posibilidad de dominar la imagen especular representa una quimera, siendo aquella el elemento constituyente del sujeto y no viceversa (Recalcati 2016: 17 y 19). ${ }^{6}$

\section{ESPEJOS SINIESTROS}

Como se ha podido comprobar, mirarse al espejo implica el ineludible enfrentamiento del sujeto con la otredad, que se traduce en la experiencia del desconocimiento de la propia imagen y, en definitiva, de uno mismo. Este proceso, aun siendo funcional, no deja de ser percibido por el individuo como traumático, ya que amenaza su afán unificador volviendo a sumirlo en el drama de la fragmentación. Sin embargo, además de la exposición espontánea y voluntaria al propio reflejo, existe otra modalidad en la que la alteridad amenaza al sujeto de forma aún más perturbadora y le sorprende cuando menos se lo espera: se trata de la experiencia de lo siniestro freudiano. Si bien el adjetivo alemán que lo designa, unheimlich, remite principalmente a lo que no es conocido o familiar -es decir, hemilich-, cabe aclarar que el fenómeno no ha de entenderse simplemente como miedo a lo desconocido, pues mucho tiene que ver precisamente con lo conocido. En efecto, unheimlich resulta ser algo que antiguamente ha sido heimlich, pero que ha dejado de serlo y ha quedado encubierto por obra de la represión (Freud 1981a: 2500). En cuanto lo reprimido aflora de repente a la conciencia, provoca una reacción perturbadora que constituye la quintaesencia de lo siniestro y se debe justamente al cambio de signo de lo conocido a lo ajeno. Si se piensa que la imagen de uno mismo, desde su cristalización a raíz del stade du miroir, es de lo más familiar para el sujeto, resulta lógico pensar que un repentino desconocimiento produzca una fuerte inquietud. También debe subrayarse la importancia del efecto sorpresivo, ya que no es lo mismo mirarse espontáneamente en un espejo que sorprenderse estando delante de él (Freud 1981a: 2502; Galimberti 2013: 320). En otras palabras, cuando el encuentro con la

\footnotetext{
${ }^{6}$ Dicha ilusión caracteriza también la experiencia de Luisa, protagonista de Fragmentos de interior, cuando, a la hora de reencontrarse con Gonzalo, las certezas de la chica vacilan, empujándola a sacar del bolso un espejito portátil, como si este pudiera fortalecer su identidad (Martín Gaite 2010b: 181). De manera análoga, en El cuarto de atrás, C. recuerda su llegada a un balneario y describe una sensación de profunda extrañeza, ante la cual reacciona mirándose a su vez en un pequeño espejo (Martín Gaite 2012a: 50-51). En ambos casos, las consecuencias son desalentadoras, ya que la imagen reflejada revela inopinadamente la alteridad intrínseca al ser humano.
} 
propia imagen es indeseado, el efecto alienante se potencia hasta desembocar en miedo (Gambazzi 1999: 71).

En varias ocasiones, Carmen Martín Gaite hace referencia a fenómenos especulares que encajan en la categoría de lo siniestro freudiano. No es insólito que algunos personajes, al encontrarse casualmente delante de un espejo, perciban su propia imagen como ajena, llegando a sentir una sensación cuando menos perturbadora. Recuérdese, como ejemplo emblemático, el comienzo de El cuarto de atrás (1978), cuando la protagonista C. está tumbada en la cama sin poder dormirse del todo. Durante el duermevela, la realidad se hace cada vez más borrosa, hasta que la mujer ya no puede distinguir si se encuentra en la habitación de su casa actual o en la de su infancia. Finalmente, frustrada por la falta de sueño, se sienta y se encuentra sin querer delante del espejo:

Me pongo de pie y se endereza el columpio, se enderezan el techo, las paredes y el marco alargado del espejo, ante el cual me quedo inmóvil, decepcionada. Dentro del azogue, la estancia se me aparece ficticia en su estática realidad, gravita a mis espaldas conforme a plomada y me da miedo, de puro estupefacta, la mirada que me devuelve esa figura excesivamente vertical, con los brazos colgando por los flancos de su pijama azul. Me vuelvo ansiosamente, desando recobrar por sorpresa la verdad en aquella dislocación atisbada hace unos instantes, pero fuera del espejo persiste la normalidad que él reflejaba, y tal vez por eso se evidencia de forma más agobiante el desorden que reina... (Martín Gaite 2012a: 24)

En primer lugar, la protagonista siente una gran decepción debido a la normalidad casi ficticia del cuarto reflejado, que traiciona sus expectativas y que la oprime con su estatismo. Pero, además de la desilusión, llega a experimentar lo siniestro: le da miedo verse y no poder reconocerse, esto es, el encuentro cara a cara con la alteridad que la concierne. De nuevo, la voluntad de alejarse de una imagen especular que no le corresponde y que la espanta está subrayada por el determinante "esa": esa figura no es su figura, no es ella. Por lo tanto, el espejo provoca aquí una escisión entre lo que $C$. cree que es y lo que realmente ve. La imagen de sí misma que la protagonista tiene asumida, lo que le es más familiar o heimlich, se convierte de repente en algo espantoso por desconocido o unheimlich, provocando cierta angustia. Asimismo, es interesante notar cómo lo siniestro no solo afecta a la mujer, sino que parece extenderse a toda la habitación, que es Heim -en alemán, el hogar-y por lo tanto heimlich, pero que aquí pierde aquel carácter de familiaridad para dejar paso a una condición insólita y desasosegante. En general, al transmitir este tipo de experiencia, la autora pretende poner de manifiesto y resaltar de manera aún más contundente la alteridad intrínseca al ser humano o, dicho en otras palabras, "el reconocimiento del extraño que nos habita" (Pittarello 2009: 30). ${ }^{7}$

7 Otro ejemplo magistral de lo siniestro freudiano puede encontrarse en el sexto capítulo de Nubosidad variable, titulado precisamente "Una prisión de espejos": en el piso de la Calle de la Amargura, donde Mariana se refugia al huir de Madrid, hay muchos espejos "solemnes, casi trágicos" que la perturban, porque le "salen al paso" y dejan aflorar cuestiones latentes hasta el 


\section{UNA VENTANA AL PASADO}

En la narrativa de Carmen Martín Gaite, el motivo del espejo no sirve solamente para destacar la imposibilidad de alcanzar la unidad del sujeto, sino que dice mucho también de la enigmática naturaleza del "yo", en cuanto superposición de una serie de identificaciones realizadas a lo largo de la vida del individuo. Así, el sujeto se configura más bien como un objeto compuesto y estratificado, al igual que una cebolla -según la metáfora propuesta por el propio Lacan (1981: 255)-. Este hecho pone en tela de juicio cualquier concepción monolítica de la identidad a la vez que subraya cómo justamente ese carácter múltiple representa su esencia (Recalcati 2016: 17).

El concepto de la estratificación, tal y como se plantea en psicoanálisis, resulta especialmente útil a la hora de comprender los mecanismos que cimientan la función del espejo como vehículo de la analepsis en la narrativa de la salmantina. Se trata, según De Bleeker, de "uno de los medios, tal vez el más importante, que permite que presente y pasado, realidad y recuerdo se comuniquen" (2006). En efecto, no es infrecuente que los personajes, en vez de verse reflejados en el espejo tal y como son actualmente, descubran una versión antigua de sí mismos o visualicen algún episodio significativo de su vida anterior a aquel momento.

Dicho fenómeno puede explicarse mediante una observación del propio Lacan al respecto: "el yo está hecho de una serie de identificaciones que han representado para el sujeto un hito esencial, en cada momento histórico de su vida y de una manera dependiente de las circunstancias" (1983: 251). Por lo tanto, la evocación -o simple aparición- del pasado dentro del espejo ha de interpretarse como proyección en el presente de una identificación pasada, esto es, de uno de aquellos hitos esenciales que al sumarse han ido construyendo la identidad del sujeto. Debido a las circunstancias en las que se hallan, los personajes recuperan, gracias a la intervención de una memoria a menudo involuntaria, algunas de aquellas experiencias que han marcado sus existencias. Este proceso suele activarse espontáneamente y funciona por analogía: la situación vivida en el presente se asocia a una pasada que se desplaza dentro del espejo.

Ya que el tema del recuerdo como elemento constituyente de la identidad es una constante a lo largo de toda su producción, no ha de extrañar que Carmen Martín Gaite recurra a esta función del espejo con relativa frecuencia. Un caso bastante ejemplificativo se encuentra en Irse de casa (1998), donde el recuerdo juega un papel fundamental para una persona que, como Amparo Miranda, des-

punto de que ver su propia imagen "es como sentir una cuchillada por la espalda" (Martín Gaite 2012c: 93). A este respecto, también resulta significativo el primer capítulo de Lo raro es vivir donde la protagonista Águeda Soler experimenta lo siniestro al ver reflejada en los cristales de unas ventanas -que aquí funcionan casi como espejos- la misma escena que está viviendo, pero protagonizada por su difunta madre: "se trataba más bien de una réplica de lo que estábamos representando en aquel momento el hombre alto y yo, con la diferencia de que, amparado por aquellas paredes transparentes, con quien él estaba hablando no era conmigo sino con mamá" (Martín Gaite 2011b: 18). En este caso, el efecto perturbador de lo siniestro es tan intenso que la mujer se acaba desmayando. 
pués de haberse ausentado durante años de su país de origen, repentinamente decide volver a España para redescubrirse a sí misma y encontrar sus raíces.

Tras descansar del largo viaje desde Estados Unidos, Amparo se arregla para ir a explorar su antigua ciudad natal. Antes de bajar a la calle, la mujer le echa un vistazo al periódico local, donde, para su gran sorpresa, descubre en la sección cultural una foto de Abel Bores, su antiguo amor de juventud. Saber que el hombre sigue viviendo allí, la anima definitivamente a salir de la habitación del hotel, no sin antes haber comprobado su apariencia:

Guarda las gafas, se alisa el vestido frente al espejo de tres cuerpos, sonríe, se mira los zapatos italianos carísimos, la cintura sin michelines, no representa ni cincuenta años, unos cuarenta y ocho, una mujer de cuarenta y ocho era vieja en sus tiempos, ahora no. Levanta un poco la ceja izquierda. No sé si te acuerdas de mí-dice-, ¿me invitas a dar un paseo en tu Vespa por las afueras? y está reconociendo a la hija de la modista de la calle del Olvido, que tantas veces ensayó esa frase y nunca fue capaz de decirla. (Martín Gaite 2012d: 59)

Nada más asomarse al espejo, la protagonista se ve tal y como es en el momento presente: se nota que es guapa y con buen gusto para la ropa. Sin embargo, de improviso, la imagen especular adquiere otro semblante y aparece reflejada una joven ensayando las posibles palabras que le diría al chico del que está enamorada. En ella, la actual Amparo se reconoce a sí misma cuando todavía era una chica de condición humilde y no una mujer de éxito. Es decir, que vislumbra a su antiguo "yo", situado en otro tiempo y en otras circunstancias vitales. Aquí, el impacto provocado por la lectura del artículo sobre Abel Bores desencadena la proyección de una identificación pasada, la cual se corresponde con un hito importante de su adolescencia: la experiencia del enamoramiento. Además, la reflexión que el narrador propone a colación resulta de extremo interés con respecto al tema analizado:

Es curioso, uno a sí mismo siempre se reconoce por los ojos, porque en ellos es donde anida ese miedo a dejarse reconocer, a haber perdido algún eslabón de la propia herencia, el miedo es lo que une el yo de ahora con los de antes, un ansia de pesquisa que imprime al rostro la emoción más incondicional, como una lucecita al fondo de la pupila. Amparo se ve guapa y joven y al mismo tiempo lee en ella misma lo que está pensando y el deseo voraz de pensarlo en voz alta teniendo a Abel enfrente. (Martín Gaite 2012d: 60)

El reconocimiento de uno mismo se realiza, pues, a través de los ojos y gracias a los ojos, ya que, en efecto, pueden considerarse uno de los elementos menos cambiantes de la fisonomía humana. A pesar de los muchos cambios que pueden afectar al rostro de una persona, estos órganos tienden a mantener su aspecto y se configuran como rasgo distintivo del individuo. Asimismo, constituyen tradicionalmente el lugar donde afloran y se pueden observar los sentimientos de uno: son la puerta de acceso a la intimidad del individuo. Y es precisamente en ellos donde la protagonista reconoce su miedo a haber perdido una parte de sí misma, un "eslabón de la propia herencia", esto es, una de aquellas identifi- 
caciones que forman parte del complejo conjunto -nunca unitario- que es la identidad. Aquí, la autora muestra plena conciencia de la multiplicidad propia del ser humano al hablar del "yo de ahora" y de "los de antes", dejando claro que no puede existir un "yo" único, sino que este tiene que ser múltiple.

En este caso, así como en otros, ${ }^{8}$ el espejo representa el punto de partida para la recuperación del pasado. La imagen especular del presente pone en marcha el funcionamiento de la memoria, llevando a los implicados hacia otra época de su vida que suele tener una relación analógica con la situación actual. El espejo, entonces, ya no refleja la realidad, sino que deja sitio a la proyección del recuerdo. Mediante este nuevo recurso, la autora destaca cómo el sujeto no es simplemente "un aquí y un ahora", sino la suma de experiencias fundacionales que se van superponiendo. De esta manera, aunque con consecuencias menos inquietantes con respecto a las dinámicas analizadas anteriormente, la imagen especular muestra que la identidad se construye a partir de la alteridad de una serie de identificaciones.

\section{BUSCANDO AL INTERLOCUTOR}

Ciñéndose a la elaboración lacaniana, los conceptos perfilados hasta ahora remiten al registro de lo Imaginario, esto es, que atañen a la acción morfógena de la imagen especular con respecto a la formación del sujeto. A tal propósito, se ha apreciado cómo Carmen Martín Gaite registra estas dinámicas en su literatura insistiendo en la insuficiencia de la imagen especular como medio de sustento identitario, así como en la naturaleza compuesta y estratificada del "yo". El problema principal estriba en que, para la escritora, el sempiterno dilema de la identidad no se resuelve mediante la relación del individuo con el espejo, pues este no garantiza en absoluto el desarrollo personal. También desde el punto de vista psicoanalítico, para salir de la espiral viciosa de lo Imaginario, es imprescindible aceptar que "no hay imagen de identidad, reflexividad, sino relación de alteridad fundamental" (Lacan 1983: 354-355). Precisamente en esto consiste el tránsito hacia el registro de lo Simbólico, un nuevo orden superior que inaugura la dimensión de la palabra, a través de cuya práctica emerge el auténtico sujeto:

\footnotetext{
8 El uso del espejo como vehículo de la analepsis se aprecia también en dos pasajes de El cuarto de atrás: en el tercer capítulo, C. está recogiendo la mesa de la cocina y ve reflejadas en el espejo primero a una niña de ocho años y luego a una chica de dieciocho -la misma protagonista en otras épocas de su vida- que la observan con afable espíritu crítico por estar dedicándose a las tareas domésticas (Martín Gaite 2012a: 70). En el sexto capítulo, antes de reanudar la charla con el hombre vestido de negro tras recibir una extraña llamada telefónica, C. vuelve al dormitorio y se sienta delante del espejo del tocador; allí, después de un breve estupor inicial, la imagen especular la traslada a un camerino del Teatro Liceo de Salamanca, en el que una joven C. está a punto de estrenar una obra teatral (Martín Gaite 2012a: 150). En el primer caso, el espejo refleja unos dobles contrapuestos a la protagonista, mientras que en el segundo se proyecta una experiencia pasada afín al momento presente. A este respecto, también cabe mencionar el momento en el que Leonardo, protagonista de La Reina de las Nieves, baja al comedor de su antigua casa y delante de un espejo oval vuelve a experimentar la peculiar sensación de cuando el padre -antes de morir- le sacaba fotos furtiva e inesperadamente (Martín Gaite 2011a: 138). La evocación de la relación con el progenitor es posible gracias a la mediación del espejo; en este caso, sin embargo, la rememoración del pasado está asociada tan solo indirectamente con la imagen reflejada.
} 
el "sujeto del deseo" -o je-frente al fictivo "yo" -o moi- (Lacan 1983: 353-370). Así pues, lo que en el ámbito de lo Imaginario se plantea como deseo egocéntrico, autorreferencial y excluyente, dentro del orden Simbólico se traduce en la necesidad de reconocimiento por parte del Otro (Lacan 1983: 255; Recalcati 2016: 68-70). Este "Gran Otro" simboliza el grado extremo de la alteridad y, a diferencia del "pequeño otro" -es decir, el semejante-, no se puede representar. No obstante, al tratarse de una abstracción, precisa de un vehículo: la figura del interlocutor como ente que permite la práctica de la palabra y su función terapéutica. La índole simbólica de la palabra, de hecho, desvía la peligrosa identificación especular poniendo al sujeto en relación con el mundo. Se destaca así la importancia de la intersubjetividad a la hora de conocerse a uno mismo, demostrada incluso lingüísticamente por la propia naturaleza de los pronombres, puesto que "cuando salgo de 'yo' para establecer una relación viva con un ser, encuentro o planteo por necesidad un 'tú', que es, fuera de mí, la sola 'persona' imaginable" (Benveniste 1997: 168).

Del mismo modo, en la obra de Carmen Martín Gaite, para quien la conversación interpersonal representa una necesidad vital antes que literaria, la palabra hablada se concibe como auténtico medio de construcción y desarrollo del individuo (Calvi 1990: 56; Guerrero Solier 1992: 319; Jurado Morales 2003: 160). Así, la búsqueda del interlocutor se convierte en un tema que permea toda su narrativa y que converge en una teoría de la comunicación plasmada en dos ensayos, La búsqueda del interlocutor $(1973,1982)$ y El cuento de nunca acabar (1983), donde se analizan el origen, las motivaciones y las modalidades del acto comunicativo, oral y escrito. Según la escritora, el ser humano se caracteriza por un deseo innato de contar lo vivido (Martín Garzo 2011: 48). Para ello, a partir de un proceso de selección, la experiencia sufre una reelaboración que se realiza en solitario, no exenta de cierto grado de ficcionalización (Martín Gaite 2000: 23-25). Solo después se hace indispensable la presencia del interlocutor, cuya búsqueda no es tarea sencilla ni siempre fructuosa, debido a la dificultad de encontrar a alguien que disponga de una capacidad incondicional de escucha. Obviamente, en la oralidad, si no se da el anhelado hallazgo, la narración no puede tener lugar. En cambio, la escritura no plantea ningún tipo de limitación, ya que sobre el papel desaparecen las restricciones que el mundo real impone al que se presta a contar. En la dimensión de lo literario, pues, ya no es imprescindible tener enfrente a un interlocutor de carne y hueso; de modo que, si este no aparece, el escritor tiene la posibilidad de crear uno ad hoc (Martín Gaite 2000: 26-27). Por otro lado, al igual que el discurso oral, el escrito también necesita entregarse a alguien para poder funcionar y, por consiguiente, la búsqueda del interlocutor -aun cuando con distintas modalidades- subyace en ambos tipos de narración.

Sin embargo, en El cuento de nunca acabar, la autora advierte de que no es suficiente soñar con el interlocutor ideal y necesitarlo para que se materialice, sino que se le debe atraer mediante un relato esmerado, así como darle cierto margen de intervención. No hay que caer en el error de considerar al destinatario un ente pasivo, mero recogedor de información, pues en el auténtico diálogo las aportaciones son mutuas y se establecen en una relación de reciprocidad; de 
ahí que la actitud del emisor adquiera un papel central a la hora de entablar una comunicación provechosa (Martín Gaite 2009a: 115-116). Desde la infancia, ante la decepción de no haber dado con el destinatario adecuado, se pueden observar dos reacciones fundamentales, las cuales tienen importantes implicaciones sobre el tipo de narración que se producirá posteriormente. La más común e inmadura es culpar al otro por no saber escuchar y asumir una postura victimista, en cuyo caso el sujeto, en vez de cuestionar su propia capacidad narrativa, se escuda en una serie de quejas y pretextos que le sirven para eximirse de toda responsabilidad sobre lo acontecido. Se trata de lo que la autora define, por su carácter desolador y mortífero desde el punto de vista comunicativo, narración "cerrada o thanatos", un tipo de discurso egocéntrico, sombrío y autodestructivo, mediante el cual el individuo se convence del contenido de su mentira hasta llegar a encarnarla, incurriendo en lo de lo que pretendía huir: el aislamiento, la indiferencia e incluso el olvido (Martín Gaite 2009a: 117). En contraposición se encuentra la "mentira instrumental o abierta", un tipo de narración constructiva y vital de carácter lúdico que se abre hacia el exterior y se aplica a la realidad con el fin de mejorarla, depurada de todo egocentrismo y ensimismamiento (Martín Gaite 2009a: 100-101). La diferenciación entre narración "thanatos" e "instrumental" resulta especialmente útil para entender dos maneras opuestas de concebir el relato y para ver cómo estas influyen en el desarrollo personal del individuo, ya que "toda búsqueda de aprecio, de identidad, de afirmación o de confrontación con el mundo se reducen, en definitiva, a una búsqueda de interlocutor" (Martín Gaite 2000: 8).

Por lo tanto, el simple contacto con los demás no garantiza en absoluto la superación de la perversa dinámica especular: con el "pequeño otro" también puede establecerse una relación de tipo narcisista. De hecho, al igual que delante del espejo, la pretensión de reconocerse en otro ser humano está destinada al fracaso, porque se trata - una vez- más de una fantasía de identificación que no tiene en cuenta la alteridad. Las relaciones basadas en este tipo de mecanismo se nutren precisamente de la "narración thanatos" y solo sirven para alimentar los espejismos del "yo-ideal". El auténtico diálogo se basa, pues, en unas premisas personales determinadas y a menudo se desarrolla en circunstancias temporales y espaciales que resultan del todo imprevisibles. De ahí que la búsqueda y el hallazgo del interlocutor, así como el confeccionar una narración depurada de las insidias del narcisismo no sean tareas sencillas, como ilustra la autora llevando a la práctica dichas teorías en todas sus novelas. Al respecto, la crítica ha abordado el asunto mediante la dicotomía comunicación/incomunicación, resaltando, por un lado, los efectos nefastos de la falta de comunicación y, por el otro, el milagroso poder de la palabra cuando hay auténtico diálogo (Jurado Morales 2003: 162-163). En particular, la falta de comunicación y sus dramáticas consecuencias son los hilos conductores de Ritmo lento (1963) y Fragmentos de interior (1976), donde los personajes no llegan a satisfacer su profunda necesidad de interlocución, lo cual acaba impidiendo su realización personal. En cambio, frente al derrotismo experimentado en estas obras, Retahílas (1974) y El cuarto de atrás (1978) plantean respectivamente el encuentro y la invención del interlocutor, y celebran el triunfo de la palabra hablada. 


\section{LA METAFORIZACIÓN DEL ESPEJO}

En lo que al espejo se refiere, cabe recordar que en el prólogo a la primera edición de La búsqueda del interlocutor, la autora pone el acento sobre la "necesidad de espejo y de interlocución" inherente a todo ser humano, asociando lo especular con la comunicación en una relación de interdependencia (Martín Gaite 2000: 7). Si bien hasta ahora se han dado muestras de los efectos negativos que una relación narcisista con la imagen especular puede provocar en el sujeto, estas no implican la condena del espejo per se, sino que sirven más bien para denunciar una actitud psicológica perjudicial. Tanto es así que el espejo sigue siendo para la autora motivo de gran fascinación por las posibilidades que entraña: al ampliar el campo visual, este objeto se concibe como medio de autoconocimiento que pone en marcha la introspección, puesto que permite la visión del rostro, rasgo distintivo por antonomasia y parte del cuerpo donde parece concentrarse la individualidad. Si se consideran las implicaciones que de ello derivan, no extraña que el gesto tan rutinario como automático de mirarse en él se preste a adquirir nuevas significaciones. Es así como este acto se convierte para la autora en una poderosa metáfora que abarca el tema de la identidad, pero concebido ya no desde la soledad, sino a partir de la relación con los demás y, finalmente, con el Gran Otro.

De este modo, el espejo deja de ser un objeto de uso cotidiano para pasar a simbolizar el papel que juegan las otras personas en el desarrollo identitario del individuo. Esto es posible solo gracias a la interiorización de una experiencia de tipo corporal sometida a una reelaboración que la transforma y la asocia a un concepto abstracto, otorgando al proceso fenomenológico de la percepción realizado siempre mediante el cuerpo- un papel primario en la comprensión del mundo (Galimberti 2013: 47). Por ello, a la hora de transmitir lo vivido, se recurre a la metáfora, una imagen derivada de la experiencia física y, en particular, de la visión. Si se tiene en cuenta que la mente no es algo ajeno al cuerpo, sino que está "inherently embodied", puede deducirse que el sistema conceptual del ser humano -su "razón"- depende directamente de él: "[reason] is shaped crucially by the peculiarities of our human bodies [...] and by the specifics of our everyday functioning in the world" $y$ "is not purely literal, but largely metaphorical and imaginative" (Lakoff y Johnson 1999: 3-4). Por lo tanto, las actividades cotidianas influyen en el pensamiento abstracto del hombre, ayudándole a entender su propia realidad, gracias a un proceso de metaforización, ya que "la esencia de la metáfora es entender y experimentar un tipo de cosa en términos de otra" (Lakoff y Johnson 2009: 41).

Así pues, a partir de la experiencia material del espejo, que da acceso al conocimiento de uno mismo -aunque sin llegar a agotarlo-, es como se fragua la metáfora aquí analizada. La acción de verse y reconocerse en una superficie reflectante se traslada al plano de la intersubjetividad, porque, según la escritora, los demás también sirven de espejos, en la medida en que le devuelven al individuo una "imagen" de sí con la que poder identificarse. Empero, esta versión hecha de palabras no siempre resulta satisfactoria y puede revelarse 
insidiosa: del mismo modo que el espejo, el semejante también puede deformar, falsear y tergiversar al sujeto perjudicando su desarrollo identitario. Tan solo en el diálogo auténtico -la dimensión de la Palabra-, el sujeto descubre su verdad y, por ende, se encuentra a sí mismo. Esta es la tesis de fondo de un artículo significativamente titulado "Los malos espejos" (1972), donde la autora constata que "perdura [...] en nosotros esa sed de ser reflejados de una manera inédita por los demás, la sed de espejo", es decir, la necesidad universal de ver la propia identidad refrendada por el otro, que es concebido como espejo, pero de tal manera que "no nos amenazara con estar albergando en el fondo de su azogue previas versiones de nuestro ser" (Martín Gaite 2000: 19). Aquí entra en juego, una vez más, la ambivalencia del espejo, es decir, el dilema de si lo que refleja es fidedigno o está distorsionado, de si muestra la verdad o miente y, en definitiva, de si es bueno o malo.

Como ya se ha apuntado, las personas también pueden devolver una imagen distorsionada, por tener una idea preconcebida y nada auténtica de quien están reflejando: son los "malos espejos", es decir, aquellos que "no saben mirar ni leer más que lo ya mirado o leído por otros" y cuyas miradas "abominan lo intricado" (Martín Gaite 2000: 20-21), quedándose en la superficie y limitándose a "devolvernos el reflejo de una imagen indemne, congelada e inmóvil" (Martín Gaite 2009a: 112). Muy al contrario, el cometido de un "buen espejo" consiste en satisfacer "esa sed de que alguien se haga cargo de la propia imagen y la acoja sin someterla a interpretaciones" (Martín Gaite 2000: 20). Pero para ello, la superficie del espejo no puede estar enturbiada y contener de antemano ningún esbozo previo, sino que debe ser cristalina. En resumidas cuentas, lo que se busca en las personas es una mirada acogedora, paciente e incondicional, dispuesta a aceptar y entender, para que el sujeto pueda deshacerse de la "cadena de la representación habitual" propia del registro de lo Imaginario (Martín Gaite 2000: 20).

\section{BUENOS Y MALOS ESPEJOS}

La metáfora del espejo se caracteriza por su naturaleza visual e implica el uso de un campo semántico relacionado con la vista, el mirar y el rostro, elementos todos que aluden a la imagen, la apariencia y la exterioridad. Pero no se debe olvidar que en el universo de Carmen Martín Gaite dicha metáfora se sitúa dentro de una teoría de la comunicación: lo que ella quiere, tanto en la vida como en la literatura, es "espejarse en los ojos de la gente que va recogiendo [su] discurso" (Martín Gaite 2009a: 49). De modo que, en las obras de la autora, no existe identidad sin la palabra. Por su parte, el espejo entendido como objeto solo puede devolver una imagen fría y silenciosa de quien se mira en él: con la superficie lúcida no se realiza intercambio alguno, porque no hay interlocución ni cuestionamiento, sino únicamente repetición de lo idéntico. Por esta razón, en su interior puede haber -a lo sumo- monólogo, aquel discurso egocéntrico y autocompasivo que caracteriza la narración "thanatos" y con el cual se pretende que "nuestra imagen no quede despedazada" (Martín Gaite 2009a: 176). Sin em- 
bargo, tal pretensión se convierte en un esfuerzo baldío, ya que es imposible erigir una identidad monolítica sin tener en cuenta la fragmentariedad propia del ser humano. Así pues, la metáfora del espejo tal y como se ha planteado hasta ahora tiene sentido aplicada a las personas solo si se entiende como actitud del oyente para con el emisor: el interlocutor reemplaza el espejo y desempeña su función, ya que tiene el cometido de reflejar el "yo" del hablante. No obstante, como se ha atisbado, puede hacerlo de distintas maneras: si el oyente se dispone a escuchar con paciencia e interés, sin afán por criticar o juzgar, entonces es un "buen espejo" y dará pie a un intercambio enriquecedor; al contrario, si se deja influenciar por habladurías y no está dispuesto a experimentar personalmente el conocimiento del otro, se convierte en un "mal espejo" que inhibe y coarta la realización personal del sujeto en vez de promoverla (Calvi 1990: 151).

En la narrativa de Carmen Martín Gaite, la metáfora del espejo encierra una gran variedad expresiva y adquiere distintas formas y matices que tienen implicaciones diversas a nivel interpretativo, puesto que la equivalencia interlocutor-espejo no siempre resulta tan evidente como en su elaboración ensayística. En este sentido, se pueden detectar tres vertientes principales. Una de ellas atañe a los ojos, los cuales constituyen el punto de partida para llegar a esta metáfora, ya que desde antiguo se los considera "el espejo del alma". Esta variante ha de considerarse una sinécdoque, pues los ojos representan la parte por el todo -el otro, el semejante-, de tal manera que este por extensión es el espejo. Así, se destaca sobre todo la importancia de lo que se ve reflejado en los demás sobre uno mismo, como le pasa a Elvira al verse observada por Pablo Klein en Entre visillos: "Y en los ojos que levantó él para mirarla, se vio ridícula como en un espejo, con la cafetera en la mano" (Martín Gaite 1983: 205). Este recurso se emplea también en el relato "Ya ni me acuerdo" (1962), donde Juanjo, gracias a la presencia de Amparo, se reinventa a sí mismo y afirma: "Montaba para ella un personaje puro, incontaminado de las intrigas que urdían los demás para medrar. Lo veía reflejado en el brillo de sus ojos azules como en un espejo" (Martín Gaite 1986: 87). Asimismo, en un pasaje de Fragmentos de interior, Diego le suplica a Agustina en una antigua carta: “ ¡Cómo miran tus ojos, con qué fuego! Quisiera verlos siempre [...] para que le sirvan a los míos de espejo y referencia, para crear un fluido limpio de mirada que nunca se enturbie con mentiras" (Martín Gaite 2010b: 56), remarcando la necesidad común a todo ser humano de verse aceptado tal y como es.

Ya se ha subrayado que para la autora el espejo no es intrínsecamente bueno o malo, sino que su naturaleza depende de quien se mira en él. En el plano metafórico se aprecia una dinámica análoga, dependiendo de las cualidades del interlocutor y de su manera de relacionarse con los demás: cuando el mal interlocutor tiene una idea preconcebida del otro, se convierte en un espejo deformante que le devuelve una imagen distorsionada e incluso grotesca. Es el caso de David Fuente, protagonista de Ritmo lento, quien ve reflejada su contradictoria relación con el padre "en el espejo deforme que [él] mismo había fabricado" (Martín Gaite 2010a: 146). Del mismo modo, en un momento dado de la larga conversación que compone Retahílas, Eulalia afirma que los ojos de la 
criada Juana "estancan el tiempo de la infancia como espejos deformes y por eso acongojan", razón por la cual esta no puede ser para ella una superficie límpida donde mirarse (Martín Gaite 1992: 101). Tampoco lo son para Raimundo, supuesta pareja de Mariana en Nubosidad Variable, sus amigos, ya que "ni siquiera siempre se ve guapo en esos espejos de alquiler, [quienes] son como los espejos deformantes del Callejón del Gato" de reminiscencias valleinclanianas (Martín Gaite 2012c: 68).

Finalmente, la autora vuelve a remarcar el deseo más o menos consciente de verse reflejado en el otro, que lleva al sujeto a buscar voluntaria o involuntariamente un soporte humano para ello. La finalidad es conocerse y reconocerse, es decir, hallar una referencia que sirva para apuntalar la propia identidad, inaprensible de forma individual. Así que, ya sea el espejo bueno o malo, enturbiado o cristalino, siempre que se asoma a él, el individuo acaba averiguando algo sobre sí mismo imposible de descubrir en solitario. Dicha necesidad está presente de forma explícita en varios personajes de Nubosidad variable y afecta, muy al principio de la novela, a Eduardo, quien, al faltarle el apoyo visual de su mujer Sofía, "se quedaba intimidado, como siempre que no encuentra el reflejo incondicional que precisa para refrendar su nueva imagen" (Martín Gaite 2012c: 15). En cambio, Sofía ejerce de "buen espejo" para con sus hijos y así lo explicita recordando su infancia: "mi espejo giraba para dar abasto a todo, yo era un espejo de cuerpo entero que los reflejaba a ellos al mirarlos, al devolver la imagen que necesitaban para seguir existiendo" (Martín Gaite 2012c: 41-42). Análogamente, el ya mencionado Diego de Fragmentos de interior, aunque a su pesar, debe reconocer que su amigo Víctor es "el único que le conocía a fondo y le devolvía una referencia certera de su imagen", un reflejo de sí mismo que no esté deformado o falseado (Martín Gaite 2010b: 141). Por otra parte, en el caso de Águeda Soler, protagonista de Lo raro es vivir (1996), se aprecia una búsqueda de autenticidad por parte de Tomás, su pareja: "fue su primera tentativa de ponerme ante un espejo y sugerirme que me quitara alguna de mis máscaras", es decir, un intento de librarla de otro tipo de identificaciones perjudiciales para ella (Martín Gaite 2011b: 159).

\section{RECONOCERSE EN EL OtRO}

La evidente recurrencia del motivo del espejo a lo largo de la obra de Carmen Martín Gaite sugiere la importancia de un tema vinculado a una preocupación fundamental para la autora: la cuestión identitaria. En efecto, desde los comienzos, toda su literatura se plantea como búsqueda incesante de la identidad, reto apremiante donde el espejo desempeña un papel decisivo para desentrañar la verdad de los personajes y de la propia escritora, en cuanto sujetos en construcción. Ya a partir de las primeras apariciones del objeto en la narrativa, cuando este aún pretende servir como recurso mimético, se introduce la idea de que en su interior no está retratada la realidad, sino una proyección de la emotividad del individuo, que acaba influyendo en la percepción del reflejo modificándolo hacia lo irreal y lo onírico. Así pues, se arguye pronto que el empleo de este 
instrumento responde principalmente a la necesidad de ilustrar fenómenos de tipo psíquico.

En este sentido, la problemática relación de los personajes con su propia imagen especular se explica teniendo en cuenta que, según la elaboración lacaniana, la alteridad es el elemento fundador del sujeto. La extrañeza que aquellos experimentan al verse reflejados y no reconocerse se achaca precisamente a que la identidad está articulada a partir de una otredad y de una multiplicidad incómodas pero ineludibles. La necesidad, manifestada por muchos de ellos, de acudir al espejo ante una crisis identitaria representa la negación de dicha alteridad y responde a la creencia -fomentada por la ilusión de unidad implícita en la imagen especular- en un sujeto autónomo y unitario. Sin embargo, semejante fantasmática choca inevitablemente con la condición estructuralmente escindida, múltiple y "otra" del sujeto.

No obstante, pese a que Carmen Martín Gaite denuncie la insuficiencia del espejo a la hora de fortalecer la identidad, nunca llega a dictar una condena moral contra el objeto per se, sino que -muy al contrario- ensalza sus propiedades y lo carga de valores metafóricos trascendentes. De modo que, una vez desenmascaradas las trampas de lo especular, se produce una transición de lo Imaginario a lo Simbólico, entendido como el lugar del Gran Otro y de la Palabra, donde se inscribe toda la concepción literaria y vital de la escritora. Dentro de este marco conceptual, se realiza un proceso de metaforización que convierte el espejo en una poderosa metáfora de la alteridad y la intersubjetividad. Así, este pasa a simbolizar al otro, quien le devuelve al individuo una imagen con la cual poder identificarse, no sin olvidar que las insidias de lo especular pueden replantearse incluso en las relaciones interpersonales.

En definitiva, puede afirmarse que Carmen Martín Gaite va desgranando a lo largo de toda su obra la complejidad de algunos mecanismos que subyacen en el proceso de formación identitaria del sujeto, señalando el peligro de determinadas ilusiones y creencias relacionadas con la imagen especular. Así, mediante el uso del espejo y su simbología, la autora derriba el falso mito de un sujeto monolítico que se conoce y se basta a sí mismo, e indica -con humildad y cercanía- cuáles son las claves para una realización personal auténtica: la asunción definitiva de la alteridad que en todo momento acompaña al ser humano y la aceptación de la relación de intersubjetividad que une indisolublemente al individuo con sus semejantes.

\section{OBRAS CITADAS}

Baltrusaitis, Jurgis (1988): El espejo. Madrid, Miraguano.

Benveniste, Émile (1997): "La naturaleza de los pronombres". En: Problemas de lingüística general. 1. México, Siglo XXI, pp. 172-178.

Calvi, Maria Vittoria (1990): Dialogo e conversazione nella narrativa di Carmen Martín Gaite. Milán, Arcipelago. 
De Bleeker, Elisabeth (2006): "Viaje a través del azogue: El cuarto de atrás de Carmen Martín Gaite", Espéculo. Revista de estudios literarios, n. ${ }^{\circ}$ 32. En línea: <https://webs. ucm.es/info/especulo/numero32/azogue.html> [última consulta: 15.11.2018].

Eco, Umberto (1988): "De los espejos". En: De los espejos y otros ensayos. Barcelona, Lumen, pp. 11-41.

Freud, Sigmund (1981a): "Lo siniestro". En: Obras completas. 3. Ensayos XCVIII al CCIII (1916 -1938). Madrid, Biblioteca Nueva, pp. 2483-2505.

— (1981b): "Más allá del principio de placer". En: Obras completas. 3. Ensayos XCVIII al CCIII (1916 -1938). Madrid, Biblioteca Nueva, pp. 2507-2541.

Galimberti, Umberto (2013): Il corpo. Milán, Feltrinelli.

Gambazzi, Paolo (1999): L'occhio e il suo inconscio. Milán, Raffello Cortina.

Guerrero Solier, Eloisa (1992): "El interlocutor en la obra de Carmen Martín Gaite: una búsqueda incesante", Analecta Malacitana, vol. 15, n. ${ }^{\circ} 1-2$, pp. 319-331.

Jurado Morales, José (2003): La trayectoria narrativa de Carmen Martín Gaite (1925-2000). Madrid, Gredos.

Lacan, Jaques (1981): El seminario de Jaques Lacan. 1. Los escritos técnicos de Freud (19531954). Barcelona, Paidós.

_ (1983): "Introducción del Gran Otro". En: El seminario de Jaques Lacan. 2. El yo en la teoría de Freud y en la técnica psicoanalítica. Buenos Aires, Paidós, pp. 353-370.

— (2008): "El estadio del espejo como formador de la función del yo [je] tal como se nos revela en la experiencia psicoanalítica". En: Escritos. 1. México, Siglo XXI, pp. 99-105.

Lakoff, George y Johnson, Mark (1999): Philosophy in the Flesh. The Embodied Mind and its Challenge to Western Thought. Nueva York, Basic Books.

— (2009): Metáforas de la vida cotidiana. Madrid, Cátedra.

Martín Gaite, Carmen (1983): Entre visillos [1958]. Barcelona, Destino.

- (1986): Cuentos completos. Madrid, Alianza.

_ (1988): "El balneario" [1955]. En: El balneario. Barcelona, Destino, pp. 11-70.

- (1992): Retahílas [1974]. Barcelona, Destino.

— (2000): La búsqueda del interlocutor [1973, 1982]. Barcelona, Anagrama.

- (2001): Los parentescos [2001]. Barcelona, Anagrama.

- (2009a): El cuento de nunca acabar [1983]. Madrid, Siruela.

— (2009b): "El pastel del diablo" [1985]. En: Dos cuentos maravillosos. Madrid, Siruela, pp. 77-156.

_ (2010a): Ritmo lento [1963]. Madrid, Siruela.

- (2010b): Fragmentos de interior [1976]. Madrid, Siruela.

- (2011a): La Reina de las Nieves [1994]. Barcelona, Anagrama.

_ (2011b): Lo raro es vivir [1996]. Barcelona, Anagrama.

- (2012a): El cuarto de atrás [1978]. Madrid, Siruela.

- (2012b): Caperucita en Manhattan [1990]. Madrid, Siruela.

- (2012c): Nubosidad variable [1992]. Barcelona, Anagrama.

- (2012d): Irse de casa [1998]. Barcelona, Anagrama.

Martín Garzo, Gustavo (2011): "El cuento de nunca acabar. Notas de lectura", Ínsula: El legado de Carmen Martín Gaite, coord. José Teruel, n. ${ }^{\circ}$ 796-770, pp. 48-49. 
Martinell Gifre, Emma (1996): El mundo de los objetos en la obra de Carmen Martín Gaite. Cáceres, Universidad de Extremadura.

Melchior Bonnet, Sabine (1996): Historia del espejo. Barcelona, Herder.

Mora, Vicente Luis (2013): La literatura egódica. El sujeto narrativo a través del espejo. Valladolid, Universidad de Valladolid.

Paoli, Anne (1998): "Mirada sobre la relación entre espejo y personaje en algunas obras de Carmen Martín Gaite", Espéculo. Revista de estudios literarios, n. 8. En línea: <https://pendientedemigracion.ucm.es/info/especulo/cmgaite/apaoli2.htm> [última consulta: 15.11.2018].

Pérez, Janet (1995): "Structural, Thematic and Symbolic Mirrors in El cuarto de atrás and Nubosidad variable of Martín Gaite", South Central Review, vol. 12, n. ${ }^{\circ}$ 1, pp. 47-63.

Pittarello, Elide (2009): "Prólogo". En Carmen Martín Gaite: Obras completas. 2. Novelas II (1979-2000). Ed. de José Teruel. Barcelona, Galaxia Gutenberg / Círculo de Lectores, pp. 9-45.

Recalcati, Massimo (2016): Jacques Lacan. 1. Desiderio, godimento e soggettivazione. Milán, Raffaello Cortina. 